\title{
Psychometric Properties of the German Version of the Whiplash Disability Questionnaire
}

Lorin M Benneker ${ }^{1}$, Carolin Roenn ${ }^{1}$, Emin Aghayev² ${ }^{*}$, Franziska V Schoeni-Affolter ${ }^{2}$, Aristomenis Exadaktylos ${ }^{3}$, Suzanne E Anderson ${ }^{4}$, Matthias Sturzenegger ${ }^{5}$, Andre Busato ${ }^{6}$ and Paul F Heini ${ }^{1}$

${ }^{1}$ Department for Orthopaedic Surgery, Inselspital, University Hospital of Bern, Freiburgstrasse, 3010 Bern, Switzerland

2 Institute for Evaluative Research in Medicine, University of Bern, Stauffacherstrasse 78, 3014 Bern, Switzerland

${ }^{3}$ Department of Emergency Medicine, University Hospital Bern, Freiburgstrasse, 3010 Bern, Switzerland

${ }^{4}$ Medical Imaging, School of Medicine Sydney, Darlinghurst Campus, The University of Notre Dame, 104 Broadway, NSW 2007, Sydney, Australia

${ }^{5}$ Department of Neurology, Inselspital, University Hospital of Bern, Freiburgstrasse, 3010 Bern, Switzerland

${ }^{6}$ Institute of Social and Preventive Medicine, University of Bern, 3012 Bern, Switzerland

\begin{abstract}
Objective: For the management of whiplash-associated disorders the use of patient oriented disability questionnaires are of uppermost importance. The Australian whiplash disability questionnaire has a high content, face and constructs validity, and an excellent short- and medium-term reproducibility. However, until now no German version of this questionnaire is available.
\end{abstract}

Aim: A cross-cultural adaptation of the whiplash disability questionnaire for a German-speaking population with ensured retention of psychometric properties such as validity and reliability of the translated version.

Settings: Acute and chronic settings.

Subject: A total of 75 patients ( 67 acute/ 8 chronic) and a control group of 177 asymptomatic volunteers were analyzed.

Interventions: All participants completed the translated 13-item questionnaire as well as documented their current health state on a visual analog scale $\left(V^{2} S_{\text {heath }}\right)$ and a general disability questionnaire (EQ-5D) for comparison. For test-retest reliability assessment 16 chronic patients and 25 healthy persons completed the questionnaire twice with an interval of 2 weeks.

Main measures: Construct and concurrent validity and test-retest reliability.

Results : The translated version showed no floor or ceiling effects, a high internal consistency (Cronbach's alpha $=0.95$ ) and a very good inter-item correlation $(\mathrm{rho}=0.926)$. The concurrent validity testing using $E Q-5 \mathrm{D}$ score as the reference showed a significant correlation to the whiplash disability questionnaire (overall rho $=0.838$, acute patients rho $=0.749$, chronic patients $r h o=0.876 ; p<0.001$ each) and to the VAS ${ }_{\text {health }}$ (overall rho $=-0.74$, acute patients rho $=-0.66$, chronic patients $r h o=-0.65 ; p<0.001$ each). The intra-class coefficient $(0.969)$ indicated high short term reproducibility.

Discussion : The German version of the whiplash disability questionnaire is valid and reliable as outcome measure for acute and chronic study settings.

Keywords: Whiplash injuries; Cronbach's alpha; Orthopaedic

\section{Introduction}

So-called Whiplash injuries resulting from an accelerationdeceleration energy transfer to the cervical spine frequently occur in traffic accidents and results in regional neck pain, neck stiffness, headache and shoulder pain [1]. Incidence rates of Whiplash injuries vary across different studies and countries, but may be as high as 677 per 100'000 inhabitant [2]. The frequency of reported chronic whiplashassociated disorders after sustaining a whiplash injury differs across cultures and regions and varies from $0 \%$ in Lithuania and Greece, to $8 \%$ to $30 \%$ in Denmark, Norway and England to $79 \%$ in Sweden [3-7].

Recently Pinfold et al. have proposed a Whiplash specific Disability Questionnaire (WDQ) based on the Neck Disability Index of the Neck Disability Questionnaire extended with several items which Hoving et al. recommended for assessment of whiplash-associated disorders $[8,9]$. This questionnaire has shown to have a high content, face and construct validity and an excellent short- and medium term reproducibility for an Australian and Canadian population [9-11]. The aim of this study was to accomplish a cross-cultural adaptation of WDQ for a Germanspeaking population ensuring retention of its psychometric properties.

\section{Materials and Methods}

The WDlQ is a self-reported questionnaire that consists of 13 items assessing patient's neck pain and impairments of daily activities. Each of these items is scored with an 11-point numerical scale (0-10) with higher values representing poorer state. The total score ranges from 0 (no problems) to 130 (worst possible state).

For the translation into German and cross-cultural adaptation the currently recommended guidelines from the American Academy of Orthopaedic Surgeons Outcomes Committee have been followed as appropriate [12]. Two native German-speaking bilingual translators independently translated the WDQ from English into German, whereas one of them was an orthopedic surgeon and the other a professional translator without medical background. A third bilingual

*Corresponding author: Emin Aghayev, Institute for Evaluative Research in Medicine, University of Bern, Stauffacherstrasse 78, 3014 Bern, Switzerland, Tel: +41 31 631 5940; Fax: +41 31631 5931; E-mail: emin.aghayev@memcenter.unibe.ch

Received November 18, 2013; Accepted January 23, 2014; Published January 26, 2014

Citation: Benneker LM, Roenn C, Aghayev E, Schoeni-Affolter FV, Exadaktylos A, et al. (2014) Psychometric Properties of the German Version of the Whiplash Disability Questionnaire. J Spine 3: 155. doi:10.4172/2165-7939.1000155

Copyright: (c) 2014 Benneker LM, et al. This is an open-access article distributed under the terms of the Creative Commons Attribution License, which permits unrestricted use, distribution, and reproduction in any medium, provided the original author and source are credited. 
translator performed a back translation of both versions into English. Subsequently, an expert committee compared all translations and adjusted discrepancies to define a new German version that was then used in the following analysis.

Data were collected from 75 German-speaking patients who fulfilled the eligibility criteria of a prospective multicenter study with its main focus on magnetic resonance imaging findings in patients that sustained an acceleration-deceleration trauma mostly after a rear-end car collision. For the translation and validation procedure the WDQs were required to be completed at three different time points: within 48 hours, and 3 and 6 months after the accident. A visual analog scale for health state $\left(\mathrm{VAS}_{\text {health }}: 0-100\right)$ and the EQ-5D questionnaire were used in addition. The visual analog scale for health status is a self-rating of the current health state, which was used as a vertical "thermometer" $[12,13]$. There are two endpoint of the scale representing the best imaginable (100; at the top) and the worst imaginable ( 0 ; at the bottom) health state [13]. The respondent rates his/her current health state by drawing a cross line on the "thermometer". The EQ-5D combines five dimensions, which are mobility, self-care, usual activities, pain/ discomfort and anxiety/depression [13]. Each dimension has three levels: no problems, some problems, extreme problems. Setting the best possible answer to 1 and the worst possible answer to 3 a simple summary score that range between 5 and 15 can be calculated [14]

To assure comprehensibility of the WDQ a control group of 177 asymptomatic volunteers completed at one time point the WDQ, the EQ-5D and $\mathrm{VAS}_{\text {health }}$. All participants signed an informed consent form and the study was approved by the local ethical committee (Cantonal Ethic Commission of the Canton Bern KEK-No 18/05).

WDQ responses were analyzed for the presence of floor and ceiling effects. The criterion for a substantial and unacceptable floor or ceiling effect was whether $>50 \%$ of subjects selected the minimum or maximum response across all items.

Factor analysis was performed for the evaluation of the factor structure of the German version. Components with associated eigenvalue greater than 1 (Kaiser Criterion) were extracted. Validity was further assessed with inter item correlation. Internal consistency was measured by Cronbach's alpha and criterion related validity was assessed by correlating the WDQ score to the EQ-5D questionnaire score as the reference.

For the test-retest reliability 41 additional patients with a history of a whiplash injury and chronic and stable symptoms were identified in the clinic database. Sixteen of these native German-speaking patients were still under treatment for chronic whiplash-associated disorders. The patients were asked to complete the questionnaires twice with an interval of two weeks and again the presence of floor and ceiling effects were analyzed. The intra-class correlation (ICC) statistics for shortterm reliability per item was calculated as the proportion of the total variability in scores that is due to the variability among subjects.

SAS 9.1 (SAS Institute Inc., USA) was used for all analyses and the level of significance was set to 0.05 throughout the study.

\section{Results}

During translation the expert committee was required to intervene only in three items in which translations were not concordant. In a) item \#6 the word "fatigued" was translated as "ermattet" (second proposal: "erschöpft"), in b) the item \#11 the word "anger" was translated as "Verdruss", a term that also includes the concept of frustration (second proposal: "Wut/Ärger"), in c) the item \#12 the word "anxiety" as it has no direct German translation available, however, the terms 'ängstlich/ unsicher' were deemed to be appropriate. The final version of the German translation is shown in the appendix (Appendix 1).

Analysis of the demographic data showed the same age and gender structure for all patient groups (acute, chronic, control). Analysis of the EQ-5D score showed the expected floor effect in the control group of $\mathrm{n}>50 \%$ selecting the minimum response and a good distinction between controls and patients. All three ages and gender adjusted means of EQ-5D score and health status were significantly different between each other (Table 1).

No floor or ceiling effects were seen in the questionnaires (WDQ, VAS $_{\text {health }}$ and EQ-5D score) of the symptomatic patients (acute and chronic). From the initial 75 patients with symptoms 48 hours after the trauma 8 patients $(10.7 \%)$ developed chronic disorder over 6 months follow-up. The mean WDQ score of these chronic patients differed significantly already two days after trauma: 33.8 in the acute group ( 8.5 at 6-month follow-up) and 75.6 in the chronic group (60.1 at 6-month follow-up) (Table 2).

Cronbach's Alpha was 0.95 indicating an excellent internal consistency, which was also supported by the absence of extremely high inter-item correlations. The latter ranged between 0.35 and 0.84 , which can be considered as appropriate for further analysis [9]. Also the inter item correlation using the Kaiser criterion for sampling adequacy was very good with an overall value of 0.93 .

Factorial analysis shows only one factor - disability - with an eigenvalue greater than 1, like for the English version of the questionnaire. The concurrent validity testing using the EQ-5D, showed a significant correlation between the two scores (overall $\mathrm{r}=0.84$; $\mathrm{p}<0.001)$. When looking at the acute group separately, an increasing correlation over time after trauma was observed (Spearman correlation coefficients: $r=0.63$ at 0 months after trauma, $r=0.79$ at 3 months and $\mathrm{r}=0.81$ at 6 months; $\mathrm{p}<0.001$ for all coefficients). Also for the $\mathrm{VAS}_{\text {health }}$ a high correlation was seen (Spearman correlation coefficients: $r=0.52$ at 0 months after trauma, $r=0.80$ at 3 months and $r=0.72$ at 6 months).

No floor or ceiling effects were seen also in the 41 completed questionnaires. The calculated ICC coefficients of short term reliability was very high with $0.97\left(1^{\text {st }}\right.$ mean 42.5 and $2^{\text {nd }}$ mean 41.3$)$ and the

\begin{tabular}{|c|c|c|c|c|c|c|}
\hline & & $\mathbf{N}$ & Min & Mean & Max & STD \\
\hline \multirow{3}{*}{ 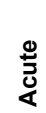 } & 0 months & 67 & 5 & 6.39 & 11 & 1.31 \\
\hline & 3 months & 67 & 5 & 5.75 & 10 & 1.09 \\
\hline & 6 months & 67 & 5 & 5.60 & 8 & 0.84 \\
\hline \multirow{3}{*}{$\begin{array}{l}\frac{0}{c} \\
\frac{0}{0} \\
\frac{1}{U}\end{array}$} & 0 months & 8 & 6 & 8.25 & 12 & 2.19 \\
\hline & 3 months & 8 & 6 & 8.75 & 11 & 1.98 \\
\hline & 6 months & 8 & 6 & 8.38 & 11 & 1.84 \\
\hline \multicolumn{2}{|c|}{ Controls at $\mathbf{0}$ months } & 177 & 5 & 5.14 & 11 & 0.56 \\
\hline
\end{tabular}

Table 1: EQ-5D scores of acute and chronic patients at the three time points and controls at 0 months.

\begin{tabular}{|c|c|c|c|c|c|c|}
\hline & & $\mathbf{N}$ & Min & Mean & Max & STD \\
\hline \multirow{3}{*}{ 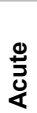 } & 0 months & 67 & 1 & 33.79 & 107 & 27.00 \\
\hline & 3 months & 67 & 0 & 15.63 & 95 & 20.11 \\
\hline & 6 months & 67 & 0 & 8.46 & 63 & 12.26 \\
\hline \multirow{3}{*}{ 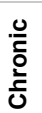 } & 0 months & 8 & 22 & 75.63 & 130 & 37.89 \\
\hline & 3 months & 8 & 20 & 66.25 & 115 & 35.74 \\
\hline & 6 months & 8 & 8 & 60.13 & 108 & 36.47 \\
\hline
\end{tabular}

Table 2: Whiplash disability scores of acute and chronic patients at the three time points. 


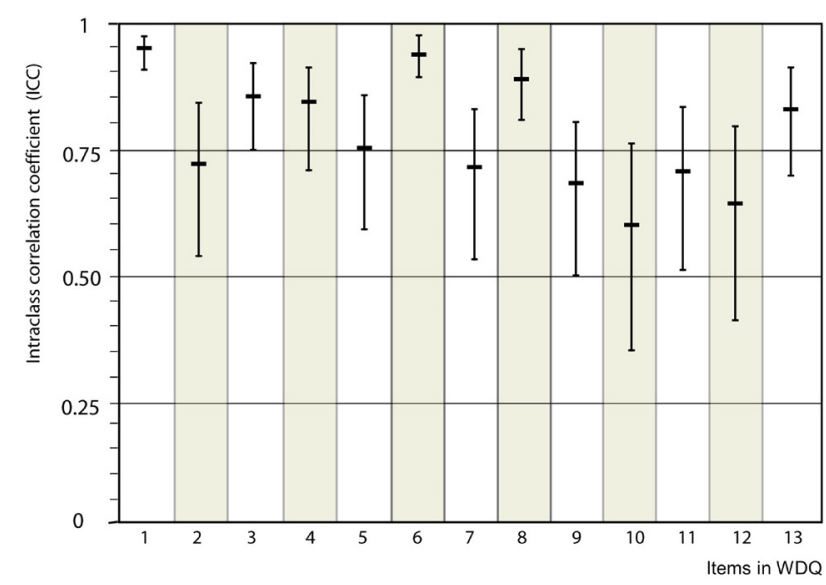

Figure 1: ICC coefficient for each of the 13 items of the German version of the WDQ questionnaire.

Cronbach's alpha was equal to 0.98 . The ICC for each of the 13 items is displayed in Figure 1. The overall ICC was 0.969.

\section{Discussions}

The translated version of the whiplash disability questionnaire showed good validity and reliability. Following the currently recommended guidelines no problems or major discrepancies were seen during the translation process or validation. No ceiling or floor effects were seen. Similarly as for the English original, the internal consistency of the German translation was excellent with a Cronbach's alpha of 0.95 (in Pinfolds original: 0.96 ) reflecting a good homogeneity of the items [15]. Concerning the construct validity, a consistent high correlation between the used measures of health/disability was found. Interestingly, the lowest correlation between all three measures was documented for the first assessment two days after trauma. Very high intra-class correlation values indicate excellent short-term reproducibility.

In contrast to Pinfolds original version of the questionnaire the German translation was tested both in chronic and acute patients [9]. A subgroup of 8 out of 75 patients with trauma and initial symptoms developed chronic disorders within 6 months of follow-up. Such proportions of patients developing chronic disorders were already reported, though that literature reports on a quite wide range of recovery rates $[3,5,6]$. Already in this small subgroup a significantly higher whiplash disability score two days after trauma was found. However, being a small subgroup of patients, their finding should be used with a certain caution. The reduction of symptoms over time was confirmed by a clear decline of the whiplash disability scores attesting a good sensitivity to change of the German version. The subgroup of chronic patients was too small to serve for identification of risk factors for poor recovery suggested in the literature [16]. The non-weighted EQ-5D score was used in the analysis. Since original publication [13] this score is currently more and more replaced by the weighted EQ-5D index that has additional Qaly feature allowing for societal valuation of quality of life [13]. The feature was not of a primary importance in the analysis, however.

In conclusion, similarly to the English original Version the German version of the whiplash disability questionnaire is as valid and reliable instrument for assessment of patient-based symptoms of whiplashassociated disorders. The simpleness of the questionnaire and the high concordance between the German and the English versions may allow for comparison of patient populations from different countries and cultures and may help in better understanding of non-somatic factors contributing to the disorders as well as in establishing effective therapies.

\section{Acknowledgements}

This project was supported by the National Research Programme NRP 53 "Musculoskeletal Health - Chronic Pain" of the Swiss National Science Foundation Project Number 405340-104531. Secondary support was also through the Van Hevesy Foundation, Rehabilitation Centre Basel, Guerbet AG CH, Swisscom AG Bern, and Inselspital Research Foundation.

\section{Clinical Messages}

The German version of the whiplash disability questionnaire is valid and reliable outcome measure for acute and chronic patients with whiplash-associate disorders.

\section{References}

1. Kasch $H$, Stengaard-Pedersen $K$, Arendt-Nielsen $L$, Staehelin Jensen $T$ (2001) Headache, neck pain, and neck mobility after acute whiplash injury: a prospective study. Spine (Phila Pa 1976) 26: 1246-1251.

2. Cassidy JD, Carroll LJ, Cote P, Frank J (2007) Does multidisciplinary rehabilitation benefit whiplash recovery?: results of a population-based incidence cohort study. Spine (Phila Pa 1976) 32: 126-131.

3. Kasch H, Bach FW, Stengaard-Pedersen K, Jensen TS (2003) Development in pain and neurologic complaints after whiplash: a 1-year prospective study. Neurology 60: 743-749.

4. Obelieniene D, Schrader H, Bovim G, Miseviciene I, Sand T (1999) Pain after whiplash: a prospective controlled inception cohort study. J Neurol Neurosurg Psychiatry 66: 279-283.

5. Partheni M, Constantoyannis C, Ferrari R, Nikiforidis G, Voulgaris S, et al. (2000) A prospective cohort study of the outcome of acute whiplash injury in Greece. Clin Exp Rheumatol 18: 67-70.

6. Borchgrevink GE, Stiles TC, Borchgrevink PC, Lereim I (1997) Personality profile among symptomatic and recovered patients with neck sprain injury, measured by MCMI-I acutely and 6 months after car accidents. J Psychosom Res 42: 357-367.

7. Olsson I, Bunketorp O, Carlsson SG, Styf J (2002) Prediction of outcome in whiplash-associated disorders using West Haven-Yale Multidimensional Pain Inventory. Clin J Pain 18: 238-244.

8. Hoving JL, O'Leary EF, Niere KR, Green S, Buchbinder R (2003) Validity of the neck disability index, Northwick Park neck pain questionnaire, and problem elicitation technique for measuring disability associated with whiplashassociated disorders. Pain 102: 273-281.

9. Pinfold M, Niere KR, O'Leary EF, Hoving JL, Green S, et al. (2004) Validity and internal consistency of a whiplash-specific disability measure. Spine (Phila Pa 1976) 29: 263-268

10. Ferrari R, Russell A, Kelly AJ (2006) Assessing whiplash recovery--the Whiplash Disability Questionnaire. Aust Fam Physician 35: 653-654

11. Willis C, Niere KR, Hoving JL, Green S, O'Leary EF, et al. (2004) Reproducibility and responsiveness of the Whiplash Disability Questionnaire. Pain 110: 681688.

12. Beaton DE, Bombardier C, Guillemin F, Ferraz MB (2000) Guidelines for the process of cross-cultural adaptation of self-report measures. Spine (Phila $\mathrm{Pa}$ 1976) 25: 3186-3191.

13. Brooks R, Rabin R, De Charro F (2003) The measurement and valuation of health status using EQ-5D: A European Persepective. Kluwer Academic Publishers, Dordrecht, Boston, London.

14. Rabin R, de Charro F (2001) EQ-5D: a measure of health status from the EuroQol Group. Ann Med 33: 337-343.

15. Streiner DL, Normal GR (1995) Health measurement scales: a practical guide to their development and use. Oxford University Press, Oxford.

16. Carroll LJ, Holm LW, Hogg-Johnson S, Cote P, Cassidy JD, et al. (2008) Course and prognostic factors for neck pain in whiplash-associated disorders (WAD): results of the Bone and Joint Decade 2000-2010 Task Force on Neck Pain and Its Associated Disorders. Spine (Phila Pa 1976) 33: S83-S92. 
Appendix 1. The German version of the Whiplash Disability Questionnaire

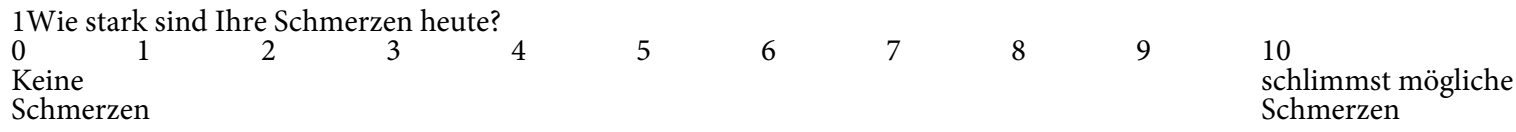

2. Wie stark beeinträchtigen die Symptome ihres Schleudertraumas ihre Körperpflege (waschen, anziehen, etc.)?

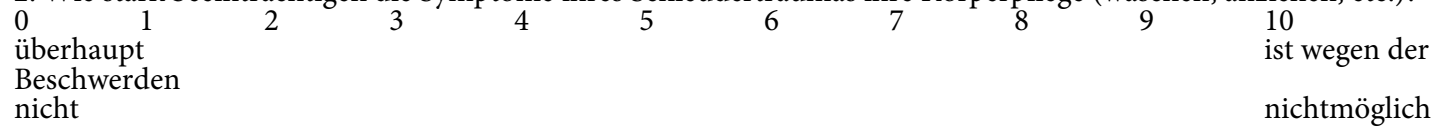

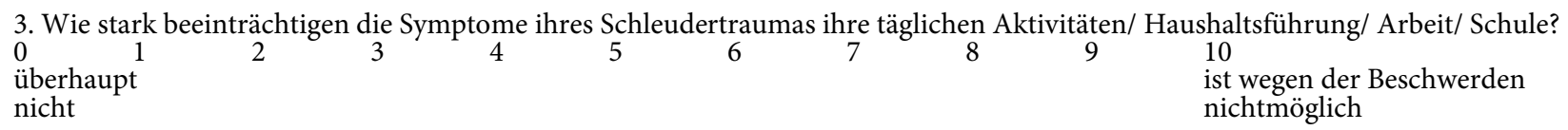

4. Wie stark haben die Symptome ihres Schleudertraumas das eigenständige Fahren oder Benutzen öffentlicher Verkehrs-mittel beeinträchtigt?

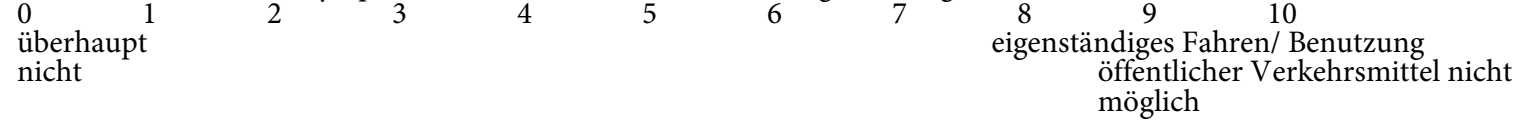
5. Wie sehr beeinträchtigen die Symptome Ihres Schleudertraumas Ihren Schlaf?
$\begin{array}{llll}\text { Überhaupt } & 8 & 9 & \text { kann nicht schlafen }\end{array}$
Nicht

6. Wie müde/ ermattet fühlen Sie sich als Folge Ihres Schleudertraumas/ der Symptome des Schleudertraumas?
überhaupt
nicht
10
ständig extrem müde/
ermattet

7. Wie sehr beeinträchtigen die Symptome Ihres Schleudertraumas Ihre gesellschaftlichen Aktivitäten?

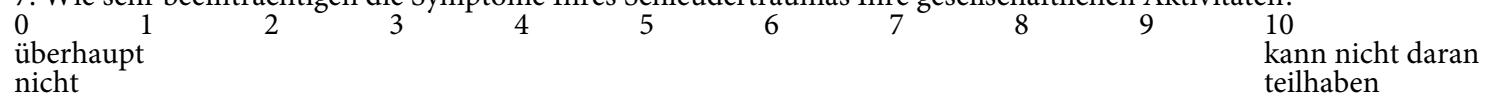

nicht

8. Wie sehr beeinträchtigen die Symptome Ihres Schleudertraumas Ihre sportlichen Freizeitaktivitäten?
$\begin{array}{llllllllll}0 & 1 & 2 & 3 & 4 & 5 & 6 & 7 & 8 & 9 \\ \end{array}$
überhaupt $\quad$ kann nicht daran
nicht teilhaben

9. Wie sehr beeinträchtigen die Symptome Ihres Schleudertraumas Ihre nicht-sportlichen Freizeitaktivitäten?

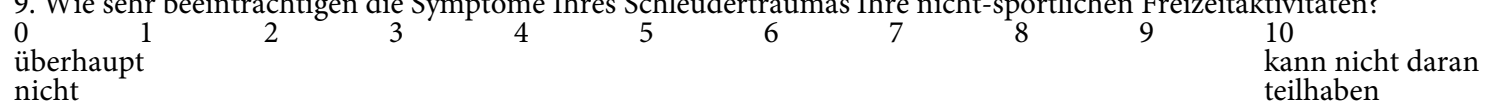

10. Sind sie traurig/ niedergeschlagen in der Folge Ihres Schleudertraumas/ der Symptome des Schleudertraumas?

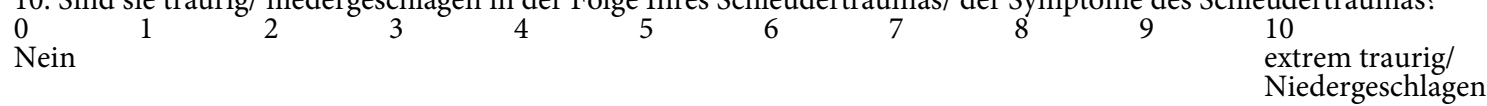

11. Wieviel Verdruss erleben sie in der Folge Ihres Schleudertraumas/ der Symptome des Schleudertraumas?

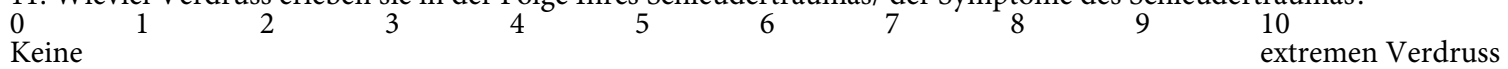

12. Sind sie ängstlich/unsicher in der Folge Ihres Schleudertraumas/ wegen der Symptome des Schleudertraumas?
$\begin{array}{llllllllll}0 & 1 & 2 & 3 & 4 & 5 & 6 & 7 & 8 & 9\end{array}$
nein extrem ängstlich/ unsicher

13. Wie groß sind Ihre Konzentrationsschwierigkeiten als Folge Ihres Schleudertraumas?
Keine
Schwierigkeiten
10
Konzentrieren ist nicht möglich 